\title{
APPLICATION OF AN UlTRASONIC SENSOR TO MONITOR SOIL EROSION AND DEPOSITION
}

\author{
Jessica E. Knox¹, Aaron R. Mittelstet ${ }^{1, *}$ \\ ${ }^{1}$ Department of Biological Systems Engineering, University of Nebraska, Lincoln, Nebraska, USA. \\ *Correspondence: amittelstet2@unl.edu.
}

\author{
HighLIGHTS \\ - A sediment monitoring system was developed to measure erosion and deposition. \\ - The system uses an ultrasonic sensor to take high-frequency measurements. \\ - Tests in controlled lab settings showed high accuracy. \\ - The system measured $43.5 \mathrm{~cm}$ of deposition from two storm events.
}

\begin{abstract}
Monitoring erosion at high temporal resolution can provide researchers and managers the data necessary to manage erosion. Current erosion monitoring methods tend to be invasive to the area of interest, record low-frequency measurements, have a narrow spatial range of measurement, or are expensive. There is a need for an affordable system capable of monitoring erosion and deposition non-invasively at high temporal resolution. The objectives of this research were to (1) design and construct a non-invasive sediment monitoring system (SMS) using an ultrasonic sensor capable of monitoring erosion and deposition continuously, (2) test the system in the lab and field, and (3) determine the applications and limitations of the system. The SMS was tested in the lab to determine the extent to which the soil type, slope, surface topography, change in distance, and vegetation impacted the measurements of the ultrasonic sensor. Soil type, slope, and surface topography had little effect on the measurement, but distance and the introduction of vegetation impacted the measurement. In the field during high flows, as erosion and deposition occurred, the changes in distance were determined in near real-time, allowing calculation of erosion and deposition quantities. The SMS was deployed to monitor deposition on sandy streambanks in the Nebraska Sandhills and erosion on a streambank and field plot in Lincoln, Nebraska. The SMS proved successful in measuring sediment change during high-flow events but yielded some error: $\pm 1.06 \mathrm{~mm}$ in controlled lab settings and $\pm 10.79 \mathrm{~mm}$ when subjected to environmental factors such as temperature, relative humidity, and wind.
\end{abstract}

Keywords. Deposition, Erosion, Monitoring, Ultrasonic sensor.

$\mathrm{E}$ rosion and deposition are natural processes that occur along the banks of rivers and streams, constantly shaping the channel. Soil erosion, specifically gulley, rill, and splash erosion, also occurs in rangeland and agricultural fields. While upland and streambank erosion occur to some degree across all landscapes, not all erosion occurs at the same rate. Natural erosion due to geological processes typically occurs slowly over time and is responsible for soil transport and the formation of topographical features such as stream channels. Accelerated erosion is human or animal induced by the removal of natural vegetation and leads to the breakdown of soil and accelerates the removal of organic and mineral particles (Schwab et al.,

Submitted for review on 4 August 2020 as manuscript number NRES 14236; approved for publication as a Research Article and as part of the Streambank Erosion, Sediment Dynamics, and Restoration: Monitoring, Modeling and Case Studies Collection by the Natural Resources \& Environmental Systems Community of ASABE on 24 February 2021.

Mention of company or trade names is for description only and does not imply endorsement by the USDA. The USDA is an equal opportunity provider and employer.
1996). However, flood events can contribute to rapid geological erosion, which can be further be compounded by human modification of the landscape (Dave and Mittelstet, 2020). Erosion reduces the productivity of agricultural lands due to soil and nutrient loss. Agricultural practices accelerate the loss of nutrients and soil at a far greater rate than can be replenished by natural processes (Amundson et al., 2015). To maintain productive agricultural lands to feed the world's growing population, extensive resources are spent to recuperate lost productivity from soil degradation and the subsequent polluting of waterways. Annually, $\$ 44$ billion is spent in the U.S. on erosion damage and control (Pimentel et al., $1995)$ and more than $\$ 1$ billion on stream restoration (Bernhardt, 2005). Incorporating conservation practices into agricultural production was reported to reduce soil loss by as much as $16 \%$ in South America and by as much as $12.5 \%$ in North America (Borrelli et al., 2017).

Long-term, continuous, accurate, and reliable data are essential to quantify the timing and amount of erosion and identify practices to reduce erosion. In some cases, erosion is measured qualitatively by visual observation and classified as either none, slight, moderate, or severe (Lal, 1994). It is 
difficult to determine quantitative amounts of erosion from these classifications. However, accurate and precise erosion measurements are necessary to develop and validate erosion models. Erosion models are useful for management and policy decisions to understand future impacts of erosion processes.

A variety of methods and devices are used to measure sediment changes (i.e., soil erosion and deposition). A traditional method is bank pins, which are stakes inserted into the area of interest (AOI) in a gridded pattern and measured over time to document the total quantity of sediment change (Thorne, 1981). Another traditional method involves repeated surveys of the bank width to document the location of the bank and its retreat (erosion) over time (Lawler, 1993; Thorne, 1981). A more modern technique is the use of photoelectric erosion pins (PEEPs), which use photovoltaic cells in series to sense incident light and output a signal, recorded continuously, that is proportional to the amount of rod exposed (Lawler, 2001). While PEEPs are typically installed to monitor erosion, they are also capable of monitoring deposition. Scour chains and sliding-bead monitors are also used to measure streambed scouring and deposition (Nawa and Frissell, 1993).

Other monitoring systems include LiDAR terrestrial laser scanning (LiDAR/TLS) and imagery from satellites or unmanned aerial vehicles (UAVs). LiDAR uses laser pulses and the measured reflected pulse to calculate the distance from the sensor to the bank surface. The lasers are sometimes mounted on a pan-tilt motor so that the entire bank can be scanned (Plenner et al., 2016; Lague et al., 2013). Analysis of satellite or UAV imagery (Cook, 2017) can also provide information on bank retreat and sediment changes. While most of these methods are deployed to monitor erosion, each has the capability to monitor deposition as well. Analysis of aerial imagery is limited for monitoring deposition, but Cook (2017) and Dave and Mittelstet (2017) were able to quantify certain amounts of deposition as well as erosion.

The following review analyzes the frequency of measurement, area measured, invasiveness to the AOI, and affordability of these different erosion monitoring methods (table 1). Of the six methods reviewed, only two record data at a high frequency, while the other methods provide data only as often as the user manually conducts measurements. Bank pins, scour chains, and stream surveys are limited in their measurement frequency by visits to the site (Thorne, 1981; Lawler, 1993). Each of these methods therefore results in erosion measurements at a low temporal resolution and is unable to provide the timing of the storm events that cause erosion.

Although PEEPs and LiDAR/TLS provide high-frequency measurements, PEEPs only provide measurements

\begin{tabular}{|c|c|c|c|c|}
\hline Method & Frequency & Area & Invasiveness & Cost \\
\hline Bank pins & Low & Point & High & Low \\
\hline Surveys & Low & Bank & Low & Low \\
\hline PEEPs & High & Point & High & Low \\
\hline LiDAR/TLS & High & Bank & Low & High \\
\hline Aerial imagery & Low & Bank & Low & Low \\
\hline Scour chains & Low & Point & Low & Low \\
\hline
\end{tabular}

during the day. They are unusable at night without incident light to indicate the amount of exposed pin (Lawler, 2001). While not restricted by time of day, TLS lacks consistency with the length of time deployed in the field. According to Plenner et al. (2016), TLS was unable to capture bank profiles immediately after storm events because it was only used during low flow. In addition, due to the equipment cost, the device was only used during certain times and was not left to monitor the bank continuously. This reduces the measurement frequency and creates knowledge gaps for erosioncausing events.

Quantifying sediment change requires continuous and accurate data that have been measured from a large area to understand the dynamics of bank movement. The six methods in table 1 are classified into two types of measurement area: point measurements and bank measurements. Bank pins, PEEPs, and scour chains provide point measurements because data are measured at the pin or chain. In contrast, LiDAR/TLS and aerial imagery can measure the sediment change of the entire bank. The lasers of a LiDAR system can be mounted on a pan-tilt motor to scan the bank to measure the bank profile (Plenner et al., 2016). Aerial imagery can capture the change in the bank or changes over the entire area from multiple images, but the resolution of the data is variable. Cook (2017) found 30 to $40 \mathrm{~cm}$ of variation between affordable UAV imaging and analysis compared to that of a LiDAR system used to measure the same sediment changes. UAVs designed for photogrammetry, which are typically expensive, can reduce this error but are still limited in their image resolution and analysis techniques (Lague et al., 2013).

Bank pins, PEEPs, and scour chains can be deployed in a gridded pattern to measure sediment change over a larger area, but this can result in reduced bank stability (except with scour chains) due to the concentration of pins that must be inserted into the area, which may influence the observed sediment change (Lawler, 2001). PEEPs are also invasive due to the cables that have to be embedded in the bank and the vegetation that must be removed so that direct light can strike the PEEP surfaces (Lawler, 1991, 2001). To reduce the influence of the monitoring method on the AOI, the method must be non-invasive. LiDAR/TLS and aerial imagery are both non-invasive methods for monitoring sediment change. Satellites and UAVs observe the AOI from above and do not influence the area. Similarly, most LiDAR/TLS systems are set a distance from the AOI, which is observed remotely using the time of reflectance of laser pulses.

From the preceding review, the most accurate, non-invasive, continuous monitoring method is LiDAR/TLS. However, while these systems provide high-quality erosion data, they tend to be very expensive. Plenner et al. (2016) created an "affordable" TLS system for approximately $\$ 10,000$. To allow multiple devices to be used for extended periods of time, they must have a much lower cost. As discussed, current erosion monitoring methods tend to be invasive to the AOI, record low-frequency measurements, have a narrow spatial range of measurement, or are very expensive. Thus, there is a need for an affordable system for monitoring erosion and deposition non-invasively at high resolution. The 
objectives of this research were to (1) design and construct a non-invasive sediment monitoring system capable of monitoring erosion and deposition continuously, (2) test the system in the lab and field, and (3) determine the applications and limitations of the system. These objectives were met by using ultrasonic sensors in conjunction with programmable electronics to develop a continuous, non-invasive erosion and deposition monitoring device for approximately $\$ 350$.

\section{Materials ANd Methods DEVElopment of SEDIMENT MONITORING SySteM}

The sediment monitoring system (SMS) consists of an ultrasonic sensor, microcontroller board (Arduino Nano), data storage electronics, compact battery, and temperature probe. The most important component is the ultrasonic sensor, for which we chose the MB7389 HRXL-MaxSonar-WR (MaxBotix Inc., Baxter, Minn.). The sensor uses the time-of-flight principle to determine the distance to a surface. A sound wave is emitted in the direction of the surface. When the sound wave strikes the surface, part of the wave bounces back and is detected by the sensor. The time between emittance and detection, in combination with the speed of sound, is used to calculate the distance to the surface by the following equation:

$$
D=\frac{1}{2}(v t)
$$

where $D$ is the distance to the surface $(\mathrm{m}), v$ is the speed of sound $\left(\mathrm{m} \mathrm{s}^{-1}\right)$, and $t$ is the time-of-flight (s).

The sensor determines the range to the nearest, largest object in the AOI (MaxBotix, 2012). When erosion or deposition occur, the sensor measures the new distance to the AOI, thus enabling the quantity of erosion or deposition to be calculated. Erosion or deposition must occur over much of the area (nearly half) to be detected as the nearest, largest object by the sensor. The sensor is also designed to detect hard-surface targets instead of soft-surface targets, making it less susceptible to vegetation and rainfall influences. However, while the sound waves can penetrate vegetation and rainfall, these factors can still impact the sensor's measuring capability. The sensor is also limited in its ability to detect submerged surfaces. In such cases, the sensor will detect the surface of the water and track the water surface elevation if it is above the AOI.

The ultrasonic sensor has a circular beam pattern with a radius of $30 \mathrm{~cm}$ and monitors an area of $2,826 \mathrm{~cm}^{2}$. This beam is dependent on the distance from the sensor. Within $30 \mathrm{~cm}$, the sensor is unable to record the distance to the AOI because there is too much interference between the emitted and reflected sound waves. Beyond $30 \mathrm{~cm}$, the sensor maintains the $30 \mathrm{~cm}$ radius beam out to its maximum range. Our research used two sensors with maximum ranges of $5 \mathrm{~m}$ (MB7389 HRXL-MaxSonar-WR) and 10 m (MB7051 XLMaxSonar-WRML).

In addition to the sensor's maximum range, there is also an inherent error in the sensor's measurement. The manufacturer reports an error of approximately $1 \%$ of the total sensing distance; this correlates to a $\pm 10 \mathrm{~mm}$ error range when sensing at a distance of $1 \mathrm{~m}$. Measuring greater distances therefore increases the error up to $\pm 100 \mathrm{~mm}$ for the $10 \mathrm{~m}$ sensor. Along with the instrument error inherent in the sensor, as reported by the manufacturer, the distance calculation is based on the speed of sound, which is impacted by environmental factors such as temperature, relative humidity, and wind (Bohn, 1988; Chen and Maher, 2004; Ingard, 1953).

In the SMS, the distance measured by the ultrasonic sensor is recorded by routing the sensor's serial output to the Arduino Nano, which boots, initiates 50 measurements, records the median value of the measurements and timestamp on the SD card module, and then returns the system to sleep mode to save battery life when not taking measurements. The sampling frequency (interval for sleep mode) and data filter can be changed within the Arduino code. For this study, the sampling frequency was set to four samples per hour, or 15 min between measurements. A deep-cycle $12 \mathrm{~V}, 22 \mathrm{Ah}$ battery was used to power the SMS for approximately one month (28 days). The date and time are kept by the real-time clock (RTC) module, which is connected to the Arduino Nano and logged to a $32 \mathrm{~GB}$ microSD card held in the SD card module when the sensor takes a measurement. The electronics and battery are enclosed in a water-resistant, weatherproof housing to protect the SMS from environmental conditions when deployed in the field (fig. 1).

The SMS also includes an external temperature probe (MaxTemp) to correct the speed of sound for the current air temperature. To meet the National Weather Service recommendations for accurate air temperature measurement (NWS, 2018, pp. 7-8), the temperature probe is mounted on the bottom of the weatherproof housing so that it is in a shaded and well-ventilated area. The temperature probe is connected directly to the ultrasonic sensor, which automatically adjusts the speed of sound for the recorded air temperature to calculate the distance to the AOI using the following equation:

$$
D=T O F \frac{20.05 \sqrt{T_{c}+273.15}}{2}
$$

where $D$ is the distance $(\mathrm{m}), T O F$ is the time-of-flight (s), and $T_{c}$ is the air temperature $\left({ }^{\circ} \mathrm{C}\right)$ (MaxBotix, 2012). The temperature range of the MaxSonar ultrasonic sensor is $40^{\circ} \mathrm{C}$ to $65^{\circ} \mathrm{C}$, which widely exceeds the average daily temperature range (MaxBotix, n.d.).

\section{CONTROLLED LABORATORY TESTS}

The SMS was first tested in a controlled lab setting (fig. 2a) to evaluate the sensor manufacturer's error specifications and determine the impact of factors that may influence the distance measured by the sensor. The tests were performed in an enclosed area (closet) to reduce any influence from external factors. The control system and battery were placed on a counter, and the ultrasonic sensor was mounted on a ring stand facing down at a pan containing soil. The dimensions of the pan were $60 \mathrm{~cm}$ length $\times 45 \mathrm{~cm}$ width. The pan width was less than the ultrasonic sensor's beam width, but the sensor measures the largest object in its field of view, which was determined to be the soil pan because changes in the soil were measured by the sensor. Changes made during 


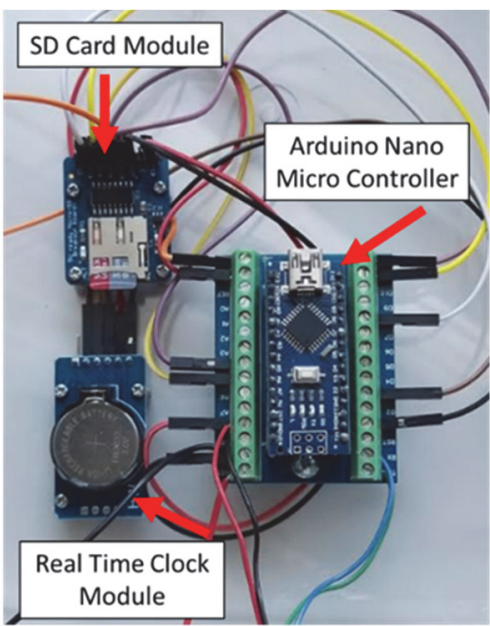

(a)

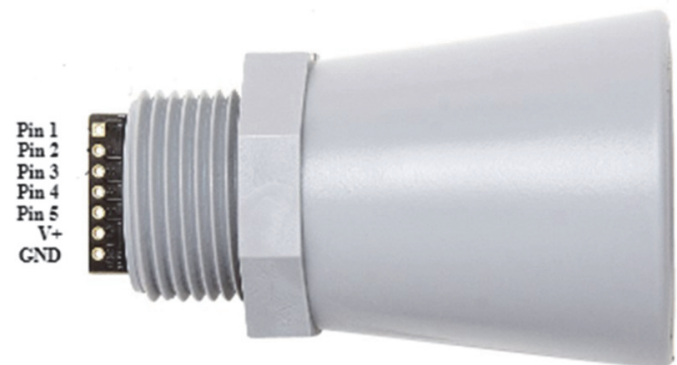

(b)

Figure 1. Components of SMS: (a) system electronics, which are installed in a weatherproof housing, and (b) $5 \mathrm{~m}$ ultrasonic sensor.

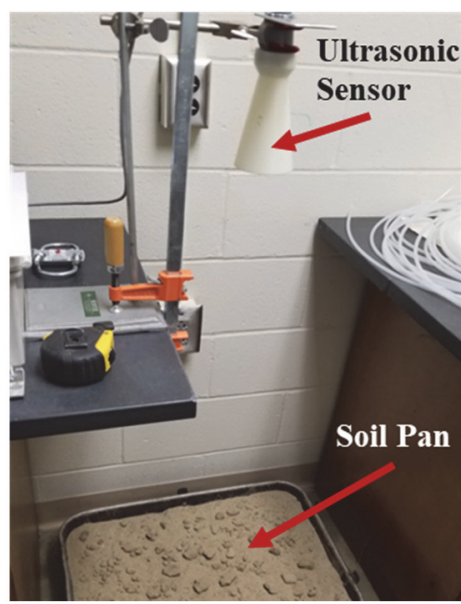

(a)

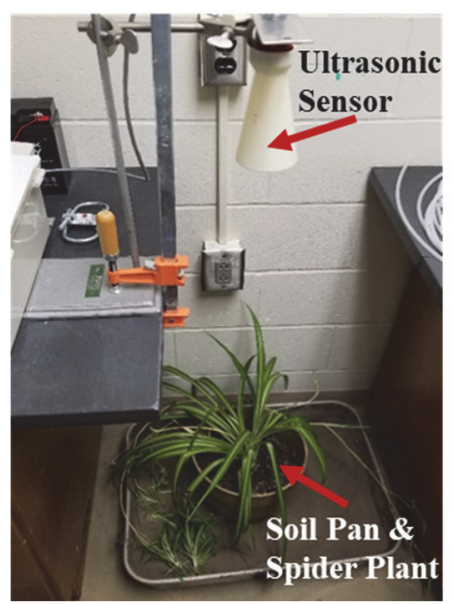

(b)

Figure 2. (a) Laboratory test setup and (b) vegetation test.

the lab tests were confirmed by manually measuring the distance from the sensor to the soil to determine the artificial erosion and deposition amounts and distance changes in the different tests.

To identify the factors that influence and limit the SMS, tests were conducted to determine the extent to which various factors influence the measurements. Seven factors were evaluated: erosion, deposition, slope, surface topography, soil type, vegetation, and distance. Each test, except when testing multiple distances, was conducted with the ultrasonic sensor remaining stationary at the same location (approx. $1.25 \mathrm{~m}$ above the soil surface). The first test investigated the ability of the SMS to monitor erosion. For this test, $22 \pm 1$ $\mathrm{mm}$ of artificial erosion (removal of sediment) was induced in the soil pan. The second test, in which $31 \pm 1 \mathrm{~mm}$ of sediment was added to the soil pan, examined deposition. The slope test consisted of tilting the soil pan to an angle of $9^{\circ}$ from horizontal. Next, a mound measuring $128 \pm 1 \mathrm{~mm}$ in elevation was created in the center of the soil pan to investigate surface topography changes. These first four tests were conducted with a sandy soil. For the fifth test, the soil was changed to a silt loam to evaluate the influence of soil type. The impact of vegetation (fig. 2b) was tested using a spider plant that was approximately $122 \pm 3 \mathrm{~mm}$ tall with a pot height of $29 \mathrm{~cm}$. The final test evaluated the sensor error at multiple distances $(1.25 \mathrm{~m}, 1.74 \mathrm{~m}$, and $2.14 \mathrm{~m})$ from the soil surface. These distances were created by increasing the height of the sensor above the soil.

\section{FIELD EXPERIMENTS}

After the system was tested in the lab, four SMSs were installed at four field sites to monitor deposition on the inside of a meander (two sites), field erosion (one site), and streambank erosion on the outside of a meander (one site). Sediment deposition was monitored at two sites in the Nebraska Sandhills: the South Branch of the Middle Loup River (SBMLR) and Sand Draw Creek. Field erosion was monitored at a UNL research facility (Rogers Memorial Farm) east of Lincoln, Nebraska. Streambank erosion was monitored on Beal Slough, a tributary to Salt Creek in Lincoln, Nebraska.

\section{Study Sites}

The SMS was set up on a sandy streambank on the SBMLR (fig. 3a), which is located within the Gudmundsen Sandhills Laboratory (GSL). The facility, owned by the University of Nebraska-Lincoln, is a research ranch located in 


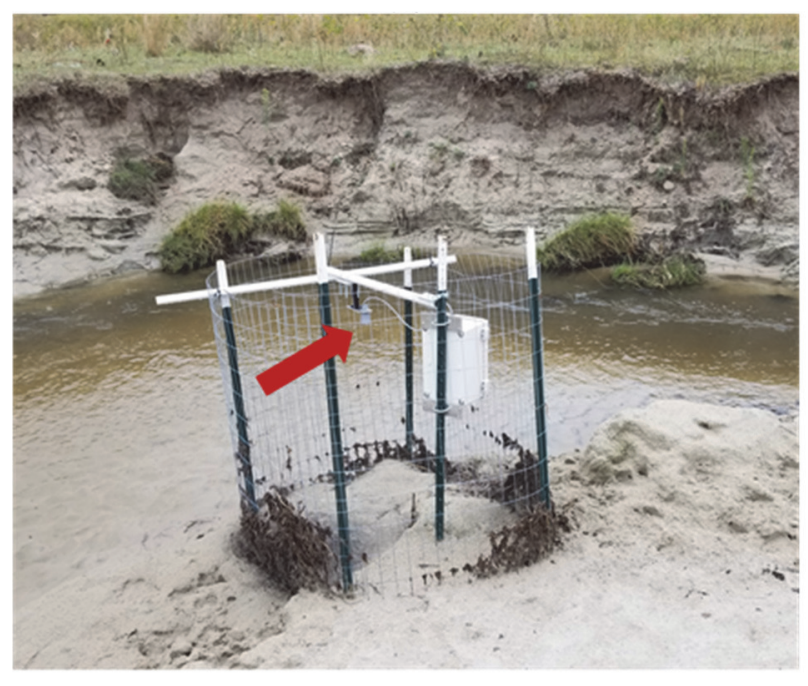

(a)

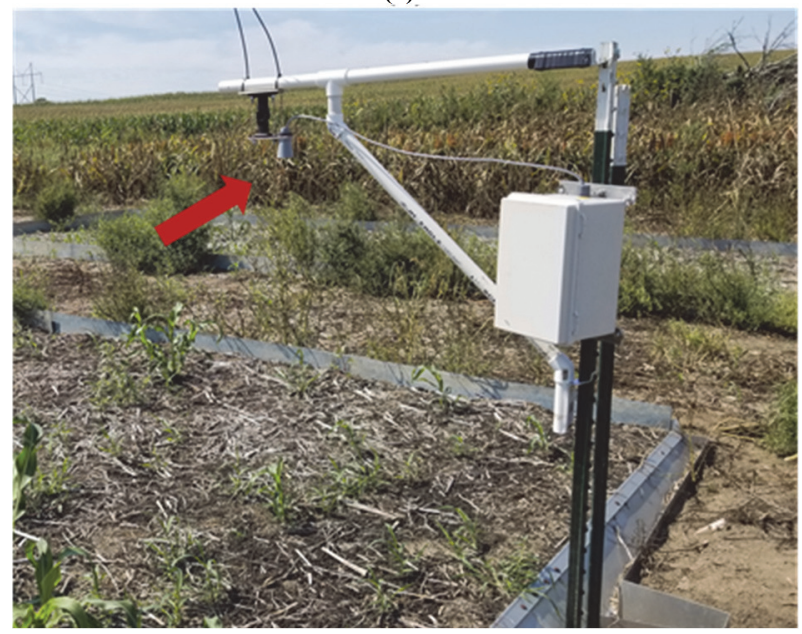

(c)

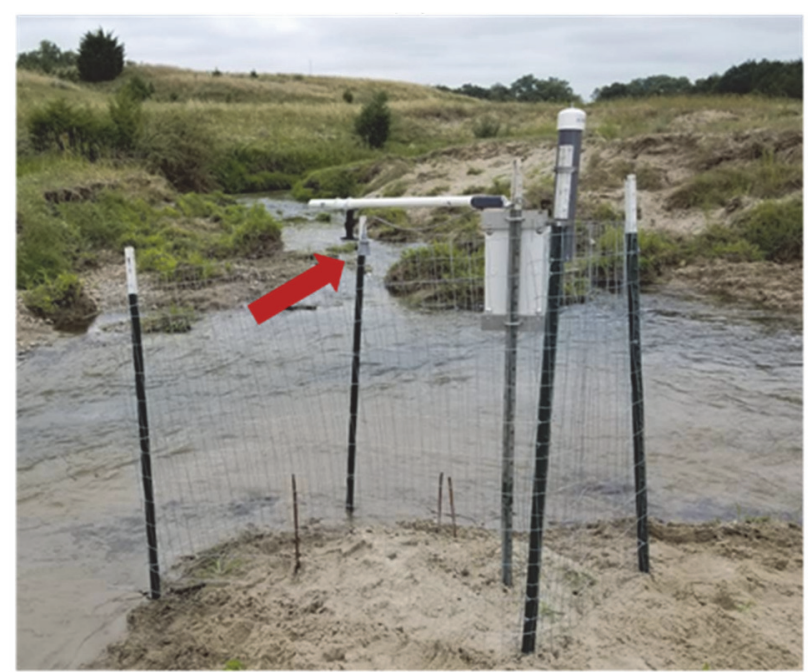

(b)

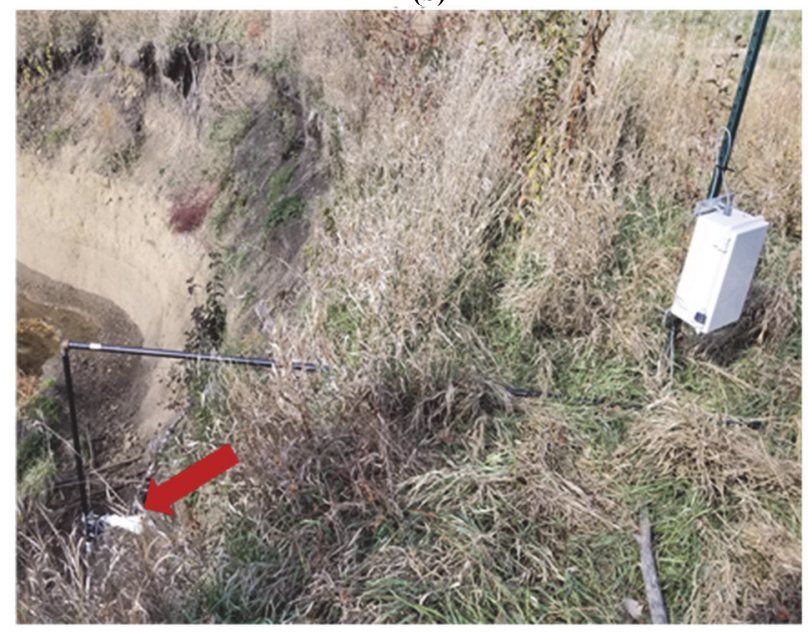

(d)

Figure 3. Four field sites used to monitor erosion and deposition with the SMS: (a) South Branch of Middle Loup River (SBMLR, deposition), (b) Sand Draw Creek (deposition), (c) Rogers Memorial Farm (field erosion), and (d) Beal Slough (streambank erosion). Red arrows indicate the location of the ultrasonic sensor.

the heart of the Sandhills in western Nebraska. Fluvial systems in the Sandhills, dominated by sandy soils, are dynamic, with erosion and deposition common during highflow events. The SMS was mounted on a horizontal arm facing downward to monitor deposition non-invasively on the point bar on the inside of a meander bend. The stream flows through a pasture; therefore, a fence was installed to protect the AOI and the SMS from cattle. While the SMS monitored the AOI non-invasively, bank pins (Thorne, 1981) were used to evaluate erosion and deposition near the AOI. Four pins were inserted into the ground, each located $40 \mathrm{~cm}$ from the center of the AOI and outside of the ultrasonic sensor's sensing area. During each visit to the site, the bank pins were measured along with the distance from the sensor to the streambed. Site visits occurred approximately every 28 days to replace the battery, download the SMS data, and record the bank pins. The SMS was deployed from the beginning of October to the end of November. The stream stage was monitored to compare the timing of sediment-altering events (likely to occur during high flows) to those captured by the SMS. The water and barometric pressure, converted to water depth, were measured using HOBO pressure transducers.
Sand Draw Creek is a small tributary to the Niobrara River in north central Nebraska. The study site (fig. 3b) was located near Ainsworth, Nebraska, in Brown County and is in the Middle Niobrara Natural Resource District. This stream is located on the edge of the Sandhills, and the predominant soil type is sand. The SMS was installed in a privately owned pasture with cattle, so a protective fence was set up around the AOI and the SMS. The ultrasonic sensor, bank pins, and HOBO pressure transducers were installed in a manner similar to the SBMLR site. The SMS was installed from August until September, when a large magnitude flood event destroyed the system. A new system was then installed from the beginning of October until the end of November and checked approximately every 28 days to replace the battery and record the bank pin information.

Rogers Memorial Farm is a research farm owned and operated by the University of Nebraska-Lincoln. The farm has historically been a no-till farm and uses terraces on the sloping fields to control sediment loss. The dominant soil type is a silty clay loam with low conductivity $\left(1 \times 10^{-8}\right.$ to 1 $\times 10^{-7} \mathrm{~m} \mathrm{~s}^{-1}$ ). Erosion was an issue before the use of no-till and terrace practices (UNL, 2020). This farm was not expected to 
produce many, if any, erosional events due to its management and was chosen to test the SMS in an agricultural setting (fig. 3c). The sensor was mounted on a horizontal arm and pointed downward to monitor a small patch of slightly sloped ground that had been tilled for a microplastics study; this AOI was chosen to increase the possibility of catching an erosion event. The non-invasiveness of the system was paramount to avoid interference with the other study being conducted on that area. Consequently, bank pins were not used at this site, but manual measurements were taken from the sensor to the ground surface. This SMS was set up from the beginning of September 2019 to early spring 2020. An updated temperature probe was installed on 14 October.

The fourth SMS was deployed in the south part of Lincoln, Nebraska, on a large cut bank experiencing erosion near a high-voltage power pole on Beal Slough, an urban waterway (fig. 3d). The SMS was mounted on the cut bank to monitor erosion. The original design was for the SMS to monitor erosion from the bank opposite the AOI. However, due to the range constraints of the ultrasonic sensor, an extended cable was attached to the sensor so that it could monitor erosion from the same bank, while the control housing was set a couple meters away from the bank edge to avoid interference or damage from streambank retreat. The cable was run through a $2.4 \mathrm{~m}$ pipe staked to the ground and extending over the eroding bank. The sensor was then mounted on a $1.2 \mathrm{~m}$ pipe that protruded vertically down from the overhanging pipe. Due to the limited accessibility to the large and steep cut bank, bank pins were not used at this site, and manual sensor-to-AOI measurements could not be conducted. Similar to the two sites in the Sandhills, a HOBO pressure transducer was used to monitor the stream depth. The SMS was deployed from mid-October 2019 to January 2020. This site was unique due to its location in an urban area, which increased the likelihood of receiving flashy runoff, and its monitoring of at-risk infrastructure.

\section{Data Analysis}

Data were analyzed using Microsoft Excel and the software environment R. Plots were constructed illustrating the

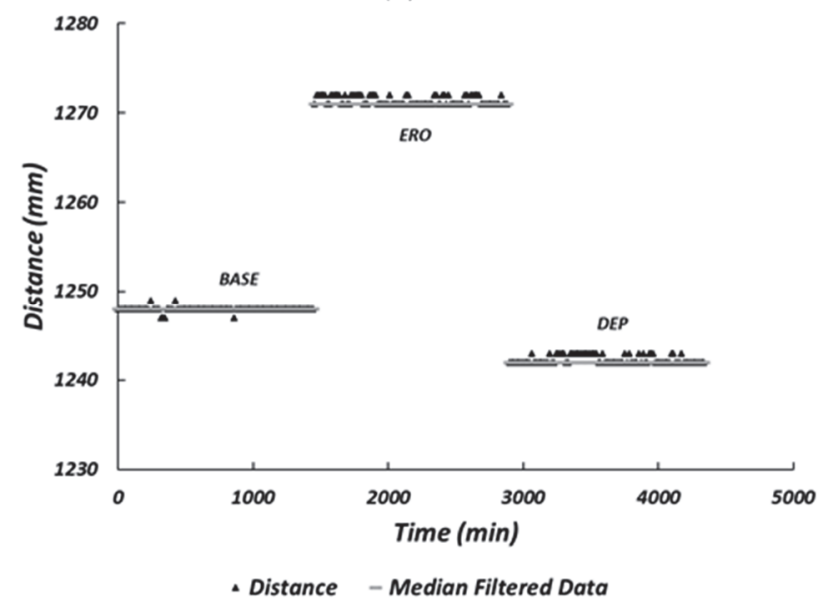

(a) measured distances against the date and time values to determine where and how much erosion or deposition occurred. Water elevation was also plotted against time, where applicable, to help determine when events occurred that would cause erosion or deposition. Once events were determined, the raw data for each event at each site was processed using the $\mathrm{R}$ data language. Outliers were removed based on box plot statistics with outliers lying outside the inner fences (NIST, n.d.). Once outliers were removed, the daily median value was determined to smooth the data and reduce the noise. The standard deviation was then calculated for each event to determine the error range (variation) of the measurement. Finally, plots were reconstructed with the filtered and smoothed data and water level data to quantify when erosional or depositional events occurred.

\section{RESULTS AND DISCUSSION \\ CONTROLlED LABORATORY TESTS}

The controlled laboratory tests helped to evaluate potential factors that could affect the results of the SMS. Initially, erosion and deposition were tested using a sandy soil. Figure $4 \mathrm{a}$ shows the different artificial erosion and deposition scenarios that were created. The SMS recorded a $23 \mathrm{~mm}$ change, with an error of $\pm 0.979 \mathrm{~mm}$, from the control $(B A S E)$ to the artificial erosion event $(E R O)$. This compares to the $22 \pm 1 \mathrm{~mm}$ of actual erosion created. Similarly, there was $29 \pm 0.945 \mathrm{~mm}$ of deposition from $E R O$ to the artificial deposition event $(D E P)$, which is comparable to the $31 \pm 1$ $\mathrm{mm}$ of actual deposition created. These findings confirm that the SMS accurately measured the erosion and deposition events.

Figure $4 \mathrm{~b}$ illustrates the results from testing the system at distances of $1.25 \mathrm{~m}(X), 1.72 \mathrm{~m}(Y)$, and $2.14 \mathrm{~m}(Z)$ above the soil. The variation was $\pm 1.06 \mathrm{~mm}$ for $1.25 \mathrm{~m}$ and then increased as the distance increased. At $1.74 \mathrm{~m}$ and $2.14 \mathrm{~m}$, the variation was $\pm 4.66 \mathrm{~mm}$ and $\pm 8.02 \mathrm{~mm}$, respectively, which is within the sensor manufacturer's stated error of $1 \%$ of the distance measured. Due to the increases in the

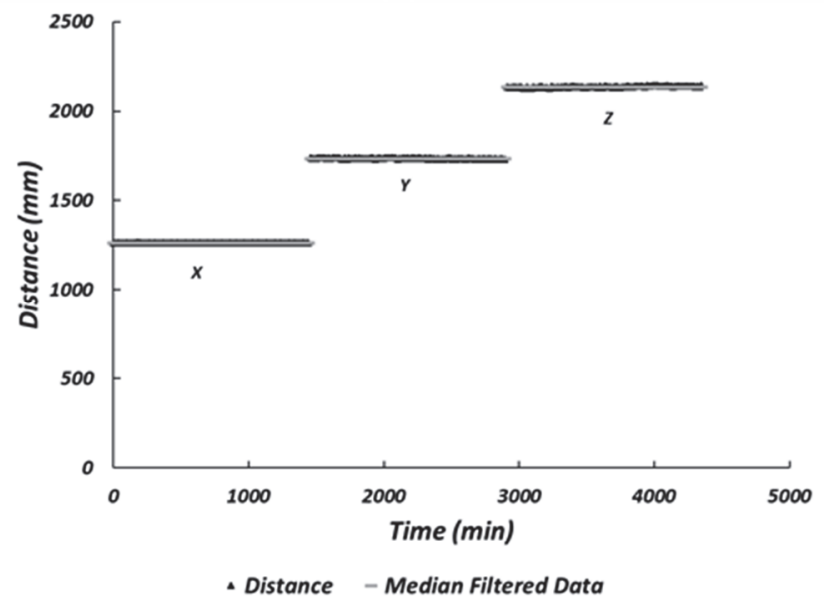

(b)

Figure 4. Results from the controlled lab tests showing (a) the control (BASE), an artificial erosion event (ERO), and an artificial deposition event $(D E P)$ and $(b)$ the differences at sensor heights of $1.25 \mathrm{~m}(X), 1.74 \mathrm{~m}(Y)$ and $2.14 \mathrm{~m}(Z)$. Most of the distance measurements occurred at the same distance as the median filtered data and are hard to denote behind the median filtered line. 


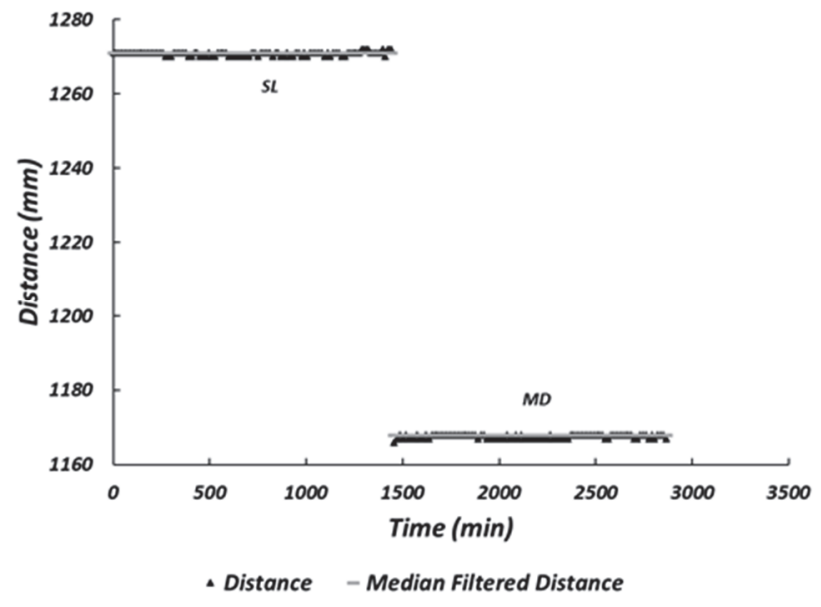

(a)

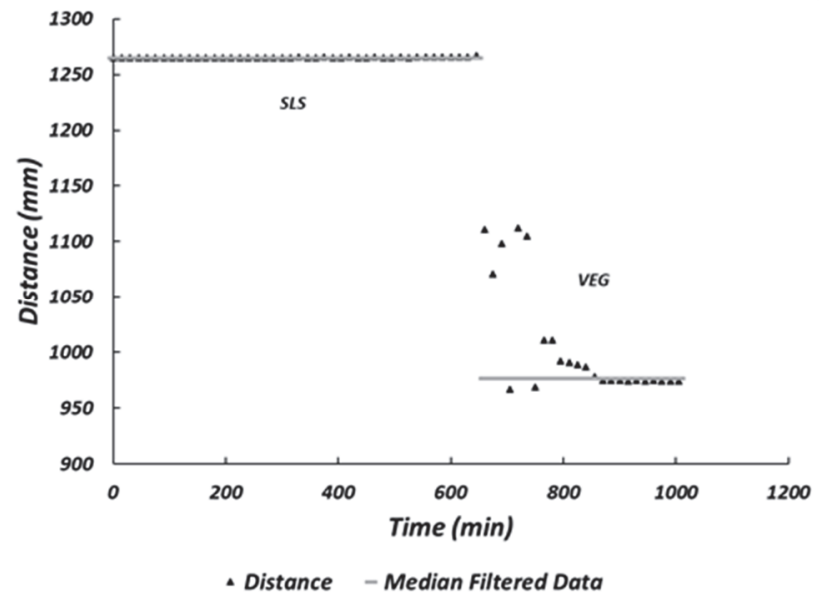

(b)

Figure 5. Results from the controlled lab tests showing (a) the slope $(S L)$ and mound $(M D)$ tests and (b) the silt loam soil type (SLS) and vegetation ( $V E G)$ test with a spider plant placed above the silt loam soil.

measurement variation at greater distances, the field experiments were designed to keep the ultrasonic sensor $\sim 1 \mathrm{~m}$ away from the AOI.

Figure 5a shows the results of the slope and mound tests, which were conducted to investigate the effects of topography. The variation in measurement for the slope test was $\pm 1.28 \mathrm{~mm}$, and the mound test had a variation of $\pm 1.18 \mathrm{~mm}$. Manual measurements indicated that the sensor was $1162 \pm 1$ $\mathrm{mm}$ above the top of the mound and $1290 \pm 1 \mathrm{~mm}$ above the bottom of the mound (i.e., the mound was $128 \mathrm{~mm}$ tall). The sensor measured to the top of the mound (the nearest, largest target) during the test, recording a value of $1164 \pm 1.18 \mathrm{~mm}$. This suggests that small changes in surface topography had little impact on the variation in the measurement; however, steeper slopes could create more variation in measurement and the sensor only measures the nearest, largest target, so the whole sensing area will be assumed to have a similar sediment change.

Figure $5 \mathrm{~b}$ show the results of changing the soil type to a silt loam $(S L S)$ and the vegetation test $(V E G)$. The silt loam soil had a variation in measurement of $\pm 1.00 \mathrm{~mm}$, which is comparable with the variation for the sandy soil of $\pm 1.06 \mathrm{~mm}$ (both tests were conducted at $1.25 \mathrm{~m}$ ). Therefore, the SMS should provide accurate results across different soil types. The spider plant was measured with a ruler to be $121 \pm 3 \mathrm{~mm}$ tall, and the SMS recorded a change in distance of approximately $123.50 \mathrm{~mm}$ between the start of the test to the end. This suggests that the SMS detected the plant near the beginning of the test, the sound waves were able to penetrate the vegetation, and the distance to the soil in the pot was recorded. These results indicate that vegetation is an important factor that can influence the sensor readings. The impacts of vegetation on the sensor readings were also seen during site visits at Rogers Memorial Farm, discussed in the following section.

\section{FIELD EXPERIMENTS}

\section{South Branch of Middle Loup River}

After the controlled laboratory tests were conducted, the SMS was tested in the field. At the SBMLR site, slight water level fluctuation $(82 \mathrm{~mm})$ and little total sediment change (11 mm) was observed by the SMS during the beginning of the monitoring period (2 to 28 October) (fig. 6a). This confirms that the SMS was able to provide stable readings during a time when there were no major changes in the AOI. The variation (error) in measurement during this time was calculated to be $\pm 11.40 \mathrm{~mm}$.

In the latter part of the study period (8 to 29 November), the SMS recorded larger measurement variations $(81 \mathrm{~mm})$, which may have been due to higher water levels and more fluctuations $(86 \mathrm{~mm})$. Small variations in sediment change across the area can be seen in the bank pin data (table 2). The measured distance to ground from 2 October to 8 November indicates that $30 \mathrm{~mm}$ of erosion occurred. The SMS showed little overall change over that period, and this highlights how non-uniform topography changes of the AOI could be missed by the SMS. The SMS data (fig. 6a) show possible erosion during the time when the system was without power (gap in the data). There was an increase in sensor measurement from $917 \mathrm{~mm}$ before power loss to $955 \mathrm{~mm}$ when power was restored, resulting in $38 \mathrm{~mm}$ of erosion possibly due to water level fluctuations. Although the average bank pin data indicated deposition over the period from 2 October to 8 November, pin 2 indicated erosion. The inconsistencies in the data can be attributed to the variability of erosion and deposition in and near the AOI.

The fence installed to protect the SMS influenced the erosion and deposition of the area as debris caught in the fence and altered the flow across the area. At this site specifically, more deposition was observed on the upstream side of the AOI (pin 2) than the downstream side (pin 4). Visual observation of the site also indicated that uneven sediment changes occurred due to debris in the fence. The pins were checked on 3 January, after the SMS lost power on 30 November, so they are not the same conditions as when the system was powered down. From 8 November to 3 January, during which time snowstorms prevented access to the site, $40 \mathrm{~mm}$ of deposition was measured from the bank pins and even more deposition $(70 \mathrm{~mm})$ was measured from the distance to ground. The bank pin deposition was due to the 


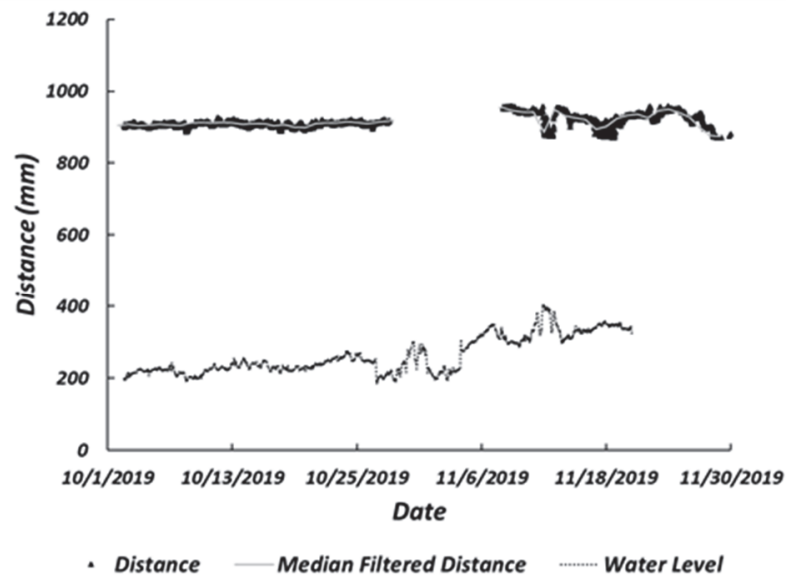

(a)

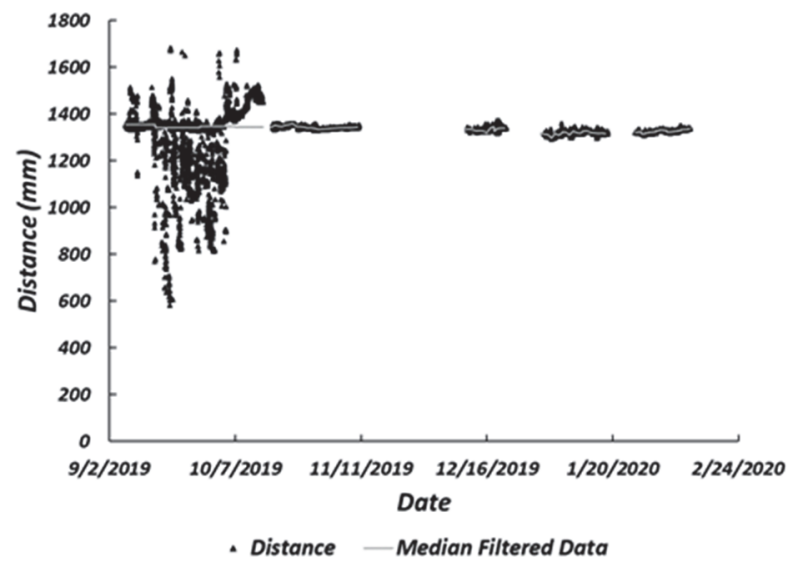

(c)

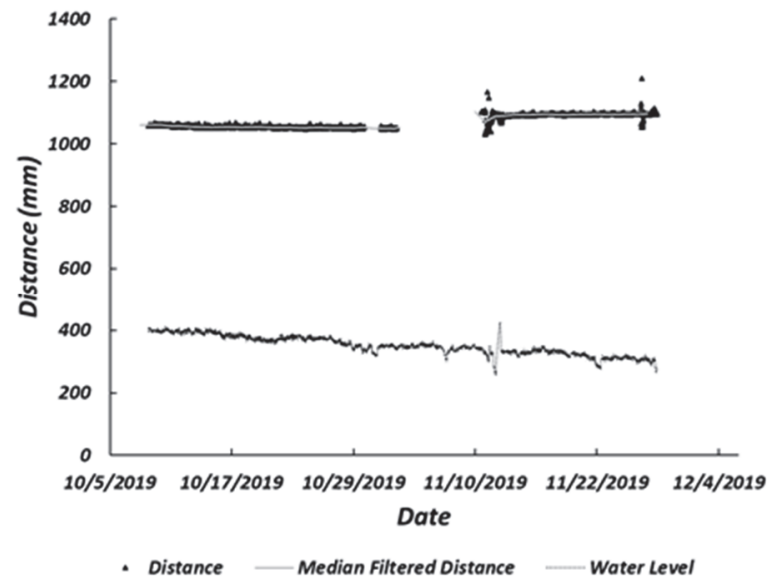

(b)

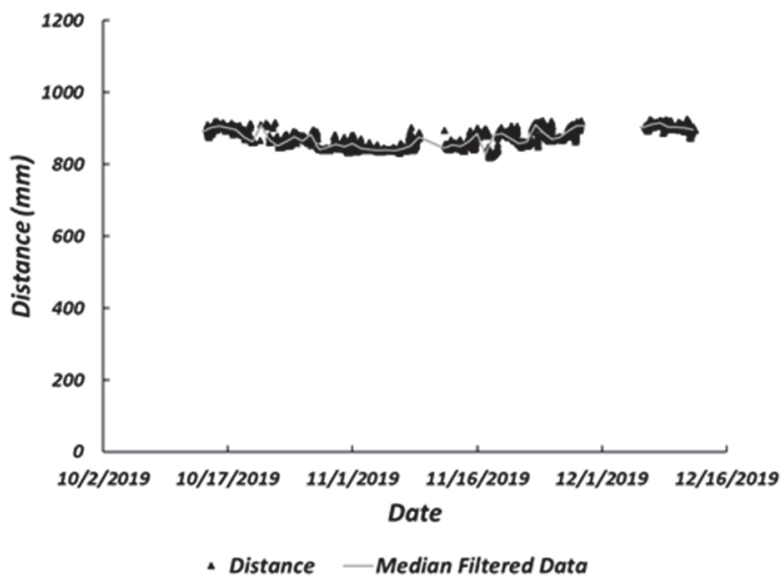

(d)

Figure 6. Results from the field sites: (a) SBMLR, (b) Sand Draw Creek post-flooding, (c) Rogers Memorial Farm, and (d) Beal Slough. Increasing distance represents erosion, and decreasing distance represents deposition.

Table 2. Results from bank pins inserted just outside of the sensing area at the SBMLR site.

\begin{tabular}{ccccccc}
\hline & $\begin{array}{c}\text { Distance } \\
\text { to Ground } \\
\text { Date }\end{array}$ & $\begin{array}{c}\text { Pin 1 } \\
(\mathrm{mm})\end{array}$ & $\begin{array}{c}\text { Pin 2 } \\
(\mathrm{mm})\end{array}$ & $\begin{array}{c}\text { Pin 3 } \\
(\mathrm{mm})\end{array}$ & $\begin{array}{c}\text { Pin 4 } \\
(\mathrm{mm})\end{array}$ & $\begin{array}{c}\text { Average } \\
\text { Change } \\
(\mathrm{mm})\end{array}$ \\
\hline 2 Oct. 2019 & 900 & 260 & 170 & 70 & 310 & - \\
8 Nov. 2019 & 930 & 237 & 183 & 70 & 235 & 21 \\
1 Jan. 2020 & 860 & 200 & 160 & 50 & 155 & 40 \\
\hline
\end{tabular}

snow and ice that accumulated over the sensing area. While the conditions on January 3 do not represent the conditions of the sensor when it lost power on 30 November, the SMS data indicate a trend of deposition that could be due to the accumulation of ice during the colder winter temperatures.

\section{Sand Draw Creek}

At the Sand Draw Creek site, the bank pin data indicate that erosion occurred in the sensing area (table 3). Furthermore, erosion at the site was much more consistent compared to the SBMLR site. From 8 October to 10 November, there was an average of $48 \mathrm{~mm}$ of erosion according to the pins, which is comparable to the approximate change of 49 $\mathrm{mm}$ based on the distance to ground measurements. The SMS data (fig. 6b) also support the magnitude of erosion measured by the pins (change of $53 \mathrm{~mm}$ ). While erosion was recorded by the pins and the SMS, the exact timing is not clear, as most of the erosion occurred in the brief period
Table 3. Results of bank pins that were inserted just outside of the sensing area at Sand Draw Creek after the system was re-installed postflooding (negative values indicate erosion).

\begin{tabular}{ccccccc}
\hline & $\begin{array}{c}\text { Distance } \\
\text { to Ground } \\
(\mathrm{mm})\end{array}$ & $\begin{array}{c}\text { Pin 1 } \\
(\mathrm{mm})\end{array}$ & $\begin{array}{c}\text { Pin 2 } \\
(\mathrm{mm})\end{array}$ & $\begin{array}{c}\text { Pin 3 } \\
(\mathrm{mm})\end{array}$ & $\begin{array}{c}\text { Pin 4 } \\
(\mathrm{mm})\end{array}$ & $\begin{array}{c}\text { Average } \\
\text { Change } \\
(\mathrm{mm})\end{array}$ \\
\hline 8 Oct. 2019 & 1054 & 285 & 267 & 553 & 258 & - \\
10 Nov. 2019 & 1103 & 410 & 270 & 555 & 307 & -48 \\
7 Dec. 2020 & 1096 & 446 & 295 & 550 & 333 & -20 \\
\hline
\end{tabular}

when the SMS was without power. Slight erosion $(20 \mathrm{~mm})$ was also measured from 10 November to 7 December by the bank pins, but the distance to ground measurement indicated little change $(7 \mathrm{~mm})$, which is consistent with the SMS data (fig. 6b). The lower magnitude of erosion measured by the SMS is likely due to water covering the sensing area. Because water was covering most of the AOI, the amount of erosion recorded by the SMS may reflect a drop in water elevation rather than sediment removal from the AOI. The measured water level decrease was $39 \mathrm{~mm}$, which is a greater reduction than was measured by the pins $(20 \mathrm{~mm})$, the distance to ground $(7 \mathrm{~mm})$, or the SMS $(6 \mathrm{~mm})$ from 10 November to 7 December. The pressure transducer was located upstream and may have had a larger change in water level than the bank location. The variation in SMS measurements was $\pm 6.1 \mathrm{~mm}$ from 8 October to 10 November and $\pm 11.5 \mathrm{~mm}$ from 10 to 27 November, indicating that the 
variation was greater than in the lab tests due to environmental factors.

The results from the Sand Draw Creek site confirm that very little sediment change occurred in the AOI during the study period. Lawler (1991) found similar steady results for a 15-day period in April 1999. He indicated that low-frequency measurements cannot support such a conclusion because "complex, but balanced, sequences of sediment deposition and removal" can occur between measurements. Only continuous time series data can affirm that no erosion or deposition occurred.

\section{Rogers Memorial Farm}

The results from Rogers Memorial Farm are shown in figure $6 \mathrm{c}$. At the beginning of the monitoring period, the measurements contained much noise and variation but then became more consistent, only showing gaps in the data when the SMS was without power. The noise in the data was due to vegetation, specifically corn, that started growing in the AOI. The data indicate that the corn grew to about $520 \mathrm{~mm}$ height through the month of September and was removed on 4 October. While the SMS measured the growth of the corn, it also detected the ground with a median value of $1343 \mathrm{~mm}$. This was consistent with the lab test results. Even though vegetation influenced the measurements from September to 4 October, consistent measurement of the ground was observed and showed minimal sediment change. The system had a manufacturer-indicated defect in the temperature probe during the start of the study period, and the probe was replaced on 14 October.

After the temperature probe was replaced, the SMS did not measure a substantial sediment-changing event and had a variation in measurement of $\pm 14.9 \mathrm{~mm}$. While there were no discrete sediment-changing events, there was gradual sediment change from December to mid-January, when $20 \mathrm{~mm}$ of sediment was gained. This could be due to sheet erosion caused by melting snow and rainfall slowly removing soil particles from upslope and carrying them downslope. While not designed to detect snow, the SMS could have measured the accumulation of snow, contributing to the variability in the measurements. Based on manual measurements, there was a $12 \mathrm{~mm}$ change between the sensor and the ground from December 10 to January 18, indicating that there was some slight accumulation of sediment during that time.

The temperatures became colder during the study period and impacted the battery life of the SMS, which is especially apparent in the gaps in the time series data from Rogers Memorial Farm. Cold temperatures caused the SMSs at all sites to have reduced battery life (approx. 14-day reduction) and become inactive until new batteries were installed.

\section{Beal Slough}

Figure $6 \mathrm{~d}$ shows the time series data from the Beal Slough cut bank site. This site had a total maximum sediment change of $92 \mathrm{~mm}$ over the monitoring time. While no bank pins were used at this site, periodic visual inspection of the bank indicated that very little erosion occurred. The water level was always much lower than the AOI, which was located near the top of the cut bank, and there was no evidence of mass wasting. The variation in measurement was $\pm 52.4 \mathrm{~mm}$, which is much higher than variations at the other sites. More variation may have occurred at this site for several reasons. The longer cable used for the SMS could have picked up external noise that impacted the signal. It is also possible that more ambient audible noise was present at this urban location that impacted the ultrasonic sensor. Finally, the combination of noise and environmental factors (relative humidity and wind) could be another reason for more variation at this site, as environmental factors caused greater variation at the other sites. Each factor had small impacts that collectively amounted to a larger variation.

\section{STRENGTHS AND Limitations OF THE SMS}

The results from the field experiments revealed greater variation in measurement compared to the controlled lab tests. This may be due to environmental impacts. While the SMS has many applications and benefits compared to traditional monitoring methods, it also has limitations with respect to the potential impacts of environmental factors. The most influential factor affecting the speed of sound is the air temperature. The speed of sound increases in warmer air and decreases in cooler air (Bohn, 1988). A temperature probe is included in the SMS to correct for the effect of air temperature on the speed of sound. However, while the temperature is corrected for, the temperature profile changes from the ground upward, creating a limitation on how well the temperature effects can be corrected. The proximity to flowing water could also impact the air temperature and relative humidity and further complicate the temperature correction.

The relative humidity is another environmental factor that can affect the speed of sound. The relative humidity is dependent on air temperature because warm air can hold more moisture than cool air. The relative humidity impacts the speed of sound because air is a medium through which sound waves travel; as the medium changes, the wave propagation will also change. At a temperature of $20^{\circ} \mathrm{C}$, the speed of sound can increase by approximately $1 \mathrm{~m} \mathrm{~s}^{-1}$ as the relative humidity increases from $0 \%$ to $100 \%$ (Chen and Maher, 2004). Coupling the effects of temperature and relative humidity, in general, sound travels faster in warmer, moister air. This means that even when accounting for temperature, the speed of sound will change as the relative humidity changes. Thus, correcting for the relative humidity would allow more precise measurements.

Wind can impact sound by changing the speed of sound depending on the direction in which the sound waves are traveling with respect to the wind direction. A sound wave is a mechanical wave traveling through a moving medium (air); as the speed of the medium changes, the speed of sound will also change. The speed of sound is relative to the speed of the medium, and the relative sound velocity is the sum of the sound velocity and wind velocity. The wind, along with temperature, can also cause refraction of sound waves, although this tends to happen over large distances and should be negligible within distances tested in this study (Ingard, 1953; Chen and Maher, 2004).

While there are limitations of the SMS with respect to environmental factors, variations in measurement could also have been caused by slight sediment changes. Lawler (1991) found that even in periods of suspected inactivity, with 
minimal water level fluctuations, frequent small-scale changes in sediment were recorded by PEEPs. The SMS in this study recorded similar small-scale changes during varying time periods at all sites. While there was no suspected activity that caused these sediment changes, wind erosion and splash erosion could influence small-scale sediment changes. The dynamics of sediment change account for the fluctuations in measurements during periods of suspected inactivity, such as at Rogers Memorial Farm and Beal Slough. These small-scale changes could have contributed to increased variations in measurements.

While the SMS is affected by environmental factors, its variation in measurement is comparable to other sediment monitoring methods. We found a \pm 6.1 to $52.4 \mathrm{~mm}$ variation in measurement for the SMS in the field, compared to \pm 1.0 to $8.0 \mathrm{~mm}$ for the lab tests. The low end of this variation, and the lab tests, is comparable to Lawler's (2001) PEEP resolution of \pm 2 to $4 \mathrm{~mm}$, but not as good as Plenner's (2016) TLS error of $0.36 \mathrm{~mm}$ between actual and measured results. While not as good as some other methods, the SMS was much better than Cook's (2017) error of 30 to $45 \mathrm{~cm}$ for UAV imagery analysis.

Although the SMS may not provide the accuracy of TLC, it has advantages over other current monitoring methods. The SMS can continuously monitor an AOI, day or night, for extended periods of time, unlike Lawler's PEEPs that work during only daytime and Plenner's TLS, which is only set up for short periods of time and only during low-flow events. The SMS is designed to accommodate water level rise above the sensing area, so it can capture the timing of sedimentaltering events and determine the exact sediment change when the water level drops. This ability is illustrated in figure 7, which shows data from Sand Draw Creek during the two distinct flood events.

Despite the defective temperature probe and the use of an average filter instead of a median filter, the SMS was still able to accurately measure the exact timing of the water level rise and subsequent deposition as the water level dropped. The first water level peak occurred on 12 August, as measured by the pressure transducer. The water level was also

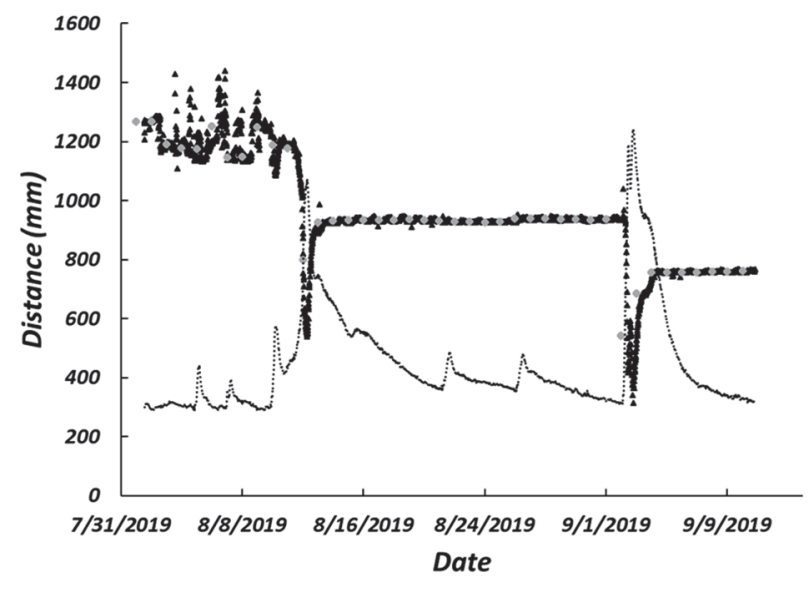

- Distance - Median Filtered Data ......... Water Level

Figure 7. Example of the ability of the SMS to capture the time of deposition events. Two large rainfall events at the Sand Draw Creek site caused major water level rise, flooding, and sediment deposition. measured by the SMS as it rose above the sensing area. As the water level decreased, the SMS measured $248 \mathrm{~mm}$ $(24.8 \mathrm{~cm})$ of sediment deposition. Another flood event measured by the pressure transducer on 2 September was also measured by the SMS. When the water level dropped, $187 \mathrm{~mm}(18.7 \mathrm{~cm})$ of deposition was recorded by the SMS. Debris built up during the flood event and caused the mounting posts to bend and flood the system. Although the SMS was ruined, the data were retrieved from the SD card. The bank pins that were inserted during this time could not be located after the substantial sediment buildup.

The results of this study demonstrate two things: the SMS has the capability of measuring the timing of erosion and deposition events, and it can provide accurate measurements (within $50 \mathrm{~mm}$, based on field measurement variations) of sediment change in the AOI. While the SMS can provide sediment change data, the measurement precision could be improved by combining the SMS with other monitoring methods. Another monitoring method would also be necessary to detect sediment change across a larger area. The SMS monitors an area of $2,826 \mathrm{~cm}^{2}$ and therefore, unlike TLS, aerial imagery, and gridded bank bins, cannot measure the sediment change for an entire bank. Combining the SMS with another affordable method, such as gridded bank pins, would allow more precise measurements of an entire bank while also providing the timing of sediment changes. Although the SMS is limited in the measurement resolution for small sediment changes, locations that undergo large sediment-changing events can be monitored with the SMS, while also recording the quantity of sediment. The high-flow events at Sand Draw Creek highlight the capability of the SMS.

\section{CONCLUSIONS AND FUTURE WORK}

We developed a sediment monitoring system (SMS) that was able to measure erosion and deposition in both the lab and field at a high temporal resolution (15 min). The SMS accurately measured the timing and quantity of two depositional events resulting from two discrete flood events on Sand Draw Creek. The SMS measured $435 \mathrm{~mm}(43.5 \mathrm{~cm})$ of sediment deposited between the two high-flow events. The controlled laboratory tests demonstrated that the SMS has a measurement variation of $\pm 1.06 \mathrm{~mm}$ at a distance of $1.25 \mathrm{~m}$, which increases slightly as the distance increases. The field experiments revealed that environmental factors influence the SMS measurements. While the air temperature is corrected for, wind and relative humidity can still impact the measurements. The measurement variation at the field sites ranged from \pm 6.12 to $52.42 \mathrm{~mm}$, with the latter variation likely being influenced by urban noise, signal noise from an extended cable, and other environmental factors.

Coupling the SMS with another erosion monitoring method would allow more precise measurement of sediment amounts while recording the timing of sediment-changing events. The SMS is limited in its ability to capture the instantaneous timing of some sediment-changing events and in its ability to measure sediment changes that are submerged by water. While it is unable to track submerged sediment 
changes, it can measure the sediment change (from before the water level rise) when the water level subsides and exposes the sediment surface.

Future work will focus on correcting for other environmental factors, such as relative humidity and wind, that can affect the sensing capability of the SMS. Increasing the battery life of the SMS is also important for long-term erosion and deposition studies. Ideally, extending the battery life to three months and incorporating a solar panel would reduce the time spent in the field and avoid potential gaps in the data. Finally, incorporating telemetry technology to transmit data from the SMS directly to users would decrease field time and ensure that data are not lost if high flows or other events destroy the SMS.

The SMS can measure sediment change continuously and non-invasively for extended periods of time. Because there is a need for a greater understanding of gully erosion, the SMS would be ideal for monitoring gullies as they become deeper and wider due to erosion. These data could then be used in developing better models for predicting gully erosion, quantifying the amount of gully erosion occurring in landscapes, and improving the management of erosionprone areas. Using interdisciplinary approaches, major challenges of managing erosion and deposition can be addressed and solved.

\section{ACKNOWLEDGEMENTS}

The authors acknowledge Santosh Pitla, Alex Drozda, and Alan Boldt from the Department of Biological Systems Engineering at the University of Nebraska-Lincoln and the U.S. Department of Agriculture, and the USDA National Institute of Food and Agriculture (Hatch Project NEB-21177). This material is also based on work supported by the National Science Foundation under Grant No. DGE1735362. Any opinions, findings, and conclusions or recommendations expressed in this material are those of the authors and do not necessarily reflect the views of the National Science Foundation.

\section{REFERENCES}

Amundson, R., Berhe, A. A., Hopmans, J. W., Olson, C., Sztein E., A., \& Sparks, D. L. (2015). Soil and human security in the 21 st century. Science, 384(6235). https://doi.org/10.1126/science.1261071

Bernhardt, E. S. (2005). Synthesizing U.S. river restoration efforts. Science, 308(5722), 636-637. https://doi.org/10.1126/science.1109769

Bohn, D. (1988). Environmental effects on the speed of sound. $J$. Audio Eng. Soc., 36(4), 223-231. Retrieved from http://www.aes.org/e-lib/browse.cfm?elib=5156

Borrelli, P., Robinson, D. A., Fleischer, L. R., Lugato, E., Ballabio, C., Alewell, C., ... Panagos, P. (2017). An assessment of the global impact of 21 st century land use change on soil erosion. Nature Comm., 8(1), article 2013. https://doi.org/10.1038/s41467-017-02142-7

Chen, Z., \& Maher, R. (2004). Atmospheric sound propagation considerations for the Birdstrike Project. Bozeman, MT: Montana State University.

Cook, K. L. (2017). An evaluation of the effectiveness of low-cost UAVs and structure from motion for geomorphic change detection. Geomorphology, 278, 195-208. https://doi.org/10.1016/j.geomorph.2016.11.009

Dave, N., \& Mittelstet, A. R. (2017). Quantifying effectiveness of streambank stabilization practices on Cedar River, Nebraska. Water, 9(12), article 930. https://doi.org/10.3390/w9120930

Dave, N., Mittelstet, A., Korus, J., \& Waszgis, M. (2020). Impact of an extreme flood event on streambank retreat: Cedar River, Nebraska, USA. JAWRA, 56(3), 528-541. https://doi.org/10.1111/1752-1688.12828

Heeren, D. M., Mittelstet, A. R., Fox, G. A., Storm, D. E., AlMadhhachi, A. T., Midgley, T. L., ... Tejral, R. D. (2012). Using rapid geomorphic assessments to assess streambank stability in Oklahoma Ozark streams. Trans. ASABE, 55(3), 957-968. https://doi.org/10.13031/2013.41527

Ingard, U. (1953). A review of the influence of meteorological conditions on sound propagation. J. Acoust. Soc. America, 25(3), 405-411. https://doi.org/10.1121/1.1907055

Lague, D., Brodu, N., \& Leroux, J. (2013). Accurate 3D comparison of complex topography with terrestrial laser scanner: Application to the Rangitikei canyon (N-Z). ISPRS J. Photogram. Remote Sensing, 82, 10-26. https://doi.org/10.1016/j.isprsjprs.2013.04.009

Lal, R. (1994). Soil erosion by wind and water: Problems and prospects. In R. Lal (Ed.), Soil erosion research methods (2nd Ed., pp. 1-7). Delray Beach, FL: St. Lucie Press. https://doi.org/10.1201/9780203739358-1

Lawler, D. M. (1991). A new technique for the automatic monitoring of erosion and deposition rates. Water Resour. Res., 27(8), 2125-2128. https://doi.org/10.1029/91WR01191

Lawler, D. M. (1993). The measurement of river bank erosion and lateral channel change: A review. Earth Surf. Proc. Landforms, 18(9), 777-821. https://doi.org/10.1002/esp.3290180905

Lawler, D. M. (2001). The photo-electronic erosion pin (PEEP) automatic erosion monitoring system: Principles and application. Proc. 7th Federal Interagency Sedimentation Conf. (vol. 1, pp. P56-P59).

MaxBotix. (2012). HRXL-MaxSonar-WR Series. Baxter, MN: MaxBotix Inc. Retrieved from https://www.maxbotix.com/documents/HRXL-MaxSonarWR Datasheet.pdf

MaxBotix. (n.d.). Temperature compensation. Baxter, MN: MaxBotix Inc. Retrieved from https://www.maxbotix.com/documents/Temperature_Compensat ion.pdf

Nawa, R. K., \& Frissell, C. A. (1993). Measuring scour and fill of gravel streambeds with scour chains and sliding-bead monitors. North American J. Fisheries Mgmt., 13(3), 634-639. https://doi.org/10.1577/15488675(1993)013<0634:MSAFOG $>2.3 . C O ; 2$

NIST. (n.d.). Section 7.1.6. What are outliers in the data? In Engineering statistics handbook. Gaithersburg, MD: National Institute of Standards and Technology. Retrieved from https://www.itl.nist.gov/div898/handbook/prc/section1/prc16.ht $\mathrm{m}$

NWS. (2018). National Weather Service Instruction 10-1302: Requirements and standards for NWS climate observations. Silver Spring, MD: National Weather Service. Retrieved from https://www.nws.noaa.gov/directives/sym/pd01013002curr.pdf

Pimentel, D., Harvey, C., Resosudarmo, P., Sinclair, K., Kurz, D., McNair, M., ... Blair, R. (1995). Environmental and economic costs of soil erosion and conservation benefits. Science, 267(5201), 1117-1123. https://doi.org/10.1126/science.267.5201.1117

Plenner, S., Eichinger, W. E., \& Bettis, E. A. (2016). Simple terrestrial laser scanner for measuring streambank retreat. $J$. 
Hydraul. Eng., 142(11), article 06016015. https://doi.org/10.1061/(ASCE)HY.1943-7900.0001184

Schwab, G. O., Fangmeier, D. D., \& Elliot, W. J. (1996). Soil and water management systems. Hoboken, NJ: John Wiley \& Sons.

Thorne, C. R. (1981). Field measurement of rates of bank erosion and bank material strength. In Erosion and sediment transport measurement. Proc. Florence symp. (pp. 503-512). IAHS Publication No. 133. Wallingford, UK: IAHS Press

UNL. (2020). Rogers Memorial Farm. Lincoln, NE: University of Nebraska, Department of Biological Systems Engineering. Retrieved from https://engineering.unl.edu/bse/bse-rogersmemorial-farm/ 